\title{
Monitoring of water supply connections as an element to reduce apparent losses of water?
}

\author{
Joanna Gwoździej-Mazur ${ }^{1, *}$ \\ ${ }^{1}$ Department of Environmental of Engineering Systems, Bialystok University of Technology, \\ ul.Wiejska 45E, Bialystok 15-351, Poland
}

\begin{abstract}
Measuring instruments are designed to measure a given physical value, to process the obtained information and forward it to the observer. They are designed to perform specific tasks in specific working conditions and meeting the envisaged requirements. The most important requirement to be met by measuring instruments, is to preserve the established metrological characteristics. The basic and most common instrument for measuring the volume of flowing water is the water meter. Selecting the right water meter in the operating conditions is not an easy issue. The problem has been further intensified by decrease of water consumption which began in the $90 \mathrm{~s}$ of the twentieth century and continuing to the present day. As a result, there has changed the structure of water consumption in both the residential and industrial applications. In this situation, a right selection of the optimal water meter it is an important case.The article presents the results of research in the field of characteristic flows in the water supply connections in multi-family housing using modern monitoring systems. It has been presented the calculated inequality ratio of water consumption, which can be helpful when designing a plumbing systems. In addition, the structure of water consumption due to the typical flow ranges was determined.
\end{abstract}

\section{Introduction}

The technical progress seen today involve great measuring capabilities that have not been used on such a wide scale until now. There are currently many modern meters for registering water flow on the market. Devices like digital loggers, ultrasound, static, or electromagnetic, together with computer software, make it possible to quickly display detailed monitoring data. The benefits of such methods are significant, including determination of correct water meter selection in a given building or determining the efficiency of internal water supply systems [1-8].

The goal of this paper is to investigate actual water flow curves on the water service pipe of a multi-family building under operating conditions as well as to determine non-uniform distribution factors and determine the structure of water consumption according to characteristic intervals describing the accuracy of measuring devices.

\footnotetext{
*Corresponding author: j.mazur@pb.edu.pl
} 


\section{Monitoring of water service pipes}

The subject of monitoring water service pipes has been present ever since water consumption was first metered in buildings. Since then, recipients have had doubts as to the metered water consumption [2, 5, 9-11]. As technology developed, so too did monitoring. The development of meter monitoring was researched as the world progressed technologically. George Theodore Paraskevakos was a pioneer in this field, and it was he who invented the sensor-based monitoring system while working for an aircraft manufacturer from Alabama in 1972. At first, this system used digital data transmission. It was used to monitor alarm systems in hospitals, fire safety systems. In 1977, George Theodore Paraskevakos started an enterprise called Metretek Instruments, which is manufacturing remote reading systems and different types of meters under the name Honeywell to this day. Automatic meter reading (AMR) - a telemetric technology involving automatic downloading of data from water, gas, heat and electricity meters and its transmission to a central database for analysis and billing. This is a way to save the human labor associated with visiting residents and reading meters. Both building administrators and residents can gain greater control of water consumption, among other things, through access to current data combined with analysis. AMR technology consists of solutions (including mobile, portable and stationary networks) based on telephone platforms (both wired and wireless), radio transmission (RF) or PLC transmission [12]. The priority underlying the introduction of automatic meter reading was not to minimize costs linked to reading, but to gain the capability of accessing a meter's data, which could not be acquired otherwise. Many water meters are installed in places that are difficult or inconvenient to access, like wells, and it is also necessary to meet with the real estate owner to conduct inspections - so many water companies began to invest in remote reading systems. The development of remote readings introduced monitoring on water service pipes, not limited to just data on water consumption. As technology advanced, it was possible to register additional data from the water meter and archive it. The development of an advanced remote reading measuring structure introduced a new type of water meter, namely ultrasound and electromagnetic water meters. The combination of a traditional water meter and a data reading module led to the creation of a single, modern measuring device, which became a tool for remote control and monitoring of water consumption $[9,10]$.

The continuous development of the measuring structure caused the definition of automatic meter reading (AMR) to evolve into advanced metering infrastructure (AMI). Advanced metering infrastructure is an integrated set of components: intelligent meters, modules and communication systems, concentrators and loggers, enabling two-way communication via various media and technologies between the central system and selected meters. Such a network makes it possible to gather data on the consumption of individual recipients, transmit control signals to devices and configure them remotely [12].

Water meters in advanced metering infrastructure are called smart meters because they process gathered data. Such metering on water service pipes forms an entire metrological network that facilitates water management. The operation of such a monitoring network provides time savings thanks to the speed of reading a water meter and limits apparent losses, which include unauthorized consumption [1, 2, 13-17].

Apparent losses are mainly the result of low accuracy of measurement of the volume of flowing water and non-simultaneity of readings of devices registering the amount of water supplied to the system (main water meter) and consumed by recipients (sub-meters on premises) $[1,2,9,10,16]$. 
Actual losses are mostly the result of a poor technical condition of the water supply system. Failures of a system's pipes, joints and fittings have the greatest impact on the size of these losses.

Benefits of an advanced water service pipe monitoring system:

- precision of flow readings,

- many parameters that can be read,

- leak detection in the system.

Despite such great technological expansion in the field of water service pipe monitoring systems in recent years, there are countries that ban the development of this technology. In India, there are many legal barriers relating to operation on radio frequencies, regardless of signal strength [8].

\section{Research methodology}

Monitoring of water consumption was conducted in multi-family buildings using static water meters with iPERL remnant field technology from Sensus (fig. 1).

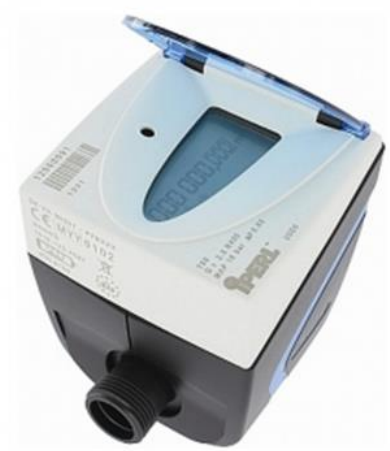

Fig. 1. iPERL water meter from the Sensus company used in tests of flow registration on the water service pipe [18].

The development of the patented remnant field technology has made the next generation of mag meter technology possible. Remanence is the magnetization left behind in a material after the external magnetic field is removed. Remanent (or residual) magnetic field technology effectively helps solve the power demands of traditional mag meter technology to serve as a viable option for the residential market. The new metering technology uses a pulse of energy to magnetize small strips of remanent material. The magnetic field is reversed each time a pulse of energy is emitted to magnetize the material, thereby inducing voltages of opposite polarity on each field flip and eliminating the effects of electrode offset which can interfere with measurement accuracy. The design of the front-end amplifier and sigma-delta analog to digital conversion contribute to improved low flow measurement accuracy over traditional battery-powered mag meters. This is critical for the detection of leaks, which is important for both the consumer and the utility company. The remanent material holds its magnetic field strength without requiring continual current consumption. In fact, remanent technology meters also conserve energy by employing low frequency field flipping to switch the magnetic field. As a result, the energy required to power the meter over the course of its lifetime is significantly reduced. This allows the meter to be powered by a traditional battery cell for the 20 -year life span required for the residential market. Another key advantage of sigma-delta analog to digital conversion is the 
ability to continuously record flow with no gaps in measurement. This is a significant advantage for a residential water meter where the flow is frequently intermittent [18].

8 multi-family buildings located in the Northeast of Poland were studied. Flowrate measurements on the water service pipe covered a period of 4 months.

An exemplary diagram of one month digital recording in one of the tested buildings, shown on figure 2 .

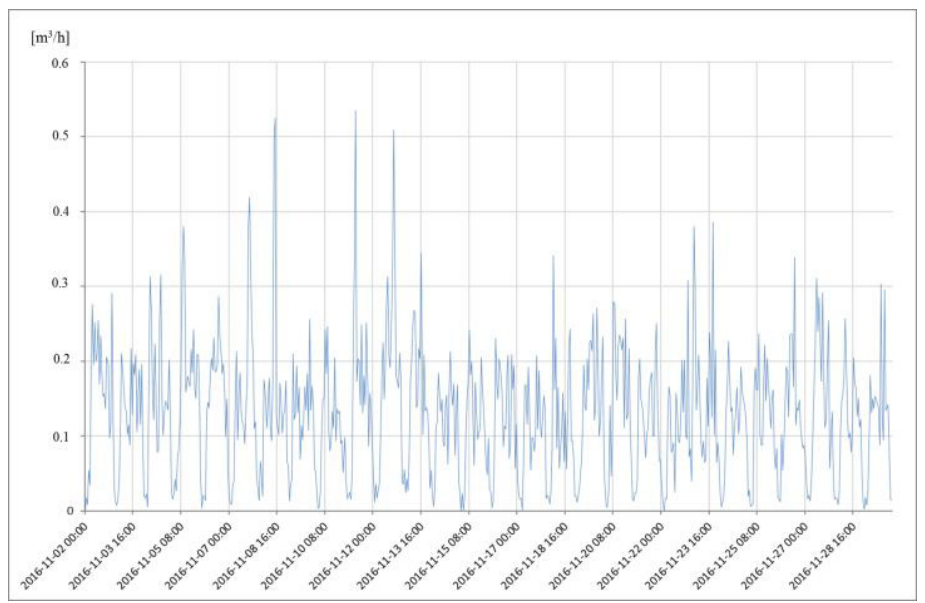

Fig. 2. Registered, average hourly water flow on the water supply connection in the tested multifamily building.

\section{Analysis of test results}

Analysis of hourly water consumption as a percentage in the studied buildings shows that flowrates up to $0.25 \mathrm{dm}^{3} / \mathrm{h}$ had the greatest share. Together, they make up approx. $82 \%$ of all minimum flows on the water service pipe. The detailed distribution of minimum flowrates depending on intervals describing the class of measuring devices installed on the water service pipe is presented in figure 3 .

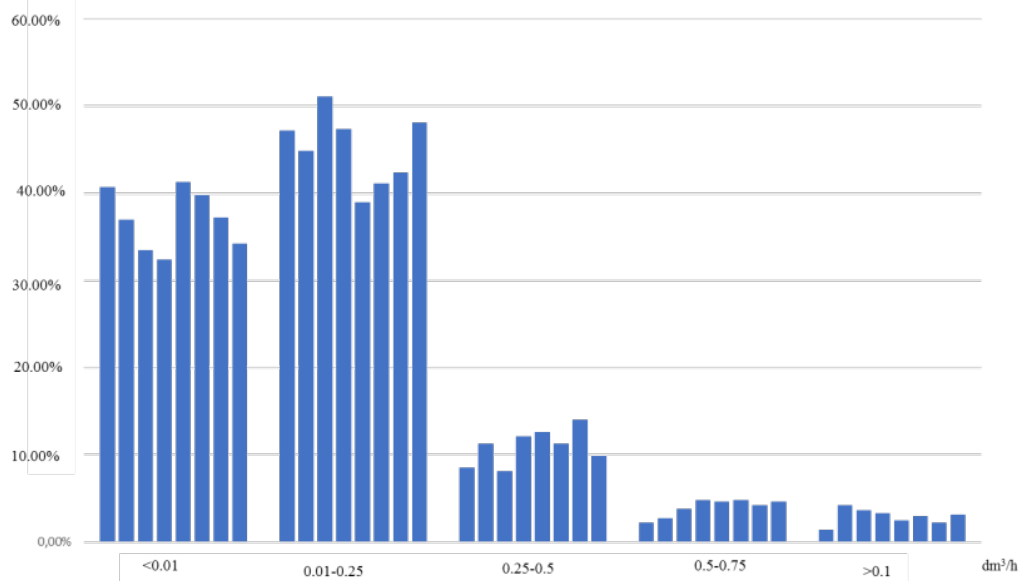

Fig. 3. Structure of hourly water consumption in selected intervals in multi-family buildings. 
Based on the analysis, the amount of apparent losses can be determined depending on the minimum volume stream. Apparent losses consist of unauthorized consumption - e.g. theft as well as losses occurring as a result of incorrect measurements and readings. The actual distribution of the minimum volume stream presented above may serve as the basis for selecting water meter's for water service pipes to multi-family buildings, and thus minimize apparent losses.

The demand for and consumption of water by its recipients is not uniform throughout the year, and it is subject to seasonal, monthly and daily fluctuations. A series of factors affect these fluctuations, including geographical location, time of the year, weather conditions and time of day. Just as there are annual, monthly and weekly fluctuations, daily fluctuations of water distributions also occur.

Daily $\left(\mathrm{N}_{\mathrm{dp}}\right)$ and hourly $\left(\mathrm{N}_{\mathrm{hp}}\right)$ non-uniformity were determined over the course of monitoring of water flowrate in service pipes. Factor values were calculated from the following formulas:

- daily non-uniformity under measuring conditions:

$$
\mathrm{N}_{\mathrm{dp}}=\mathrm{Q}_{\mathrm{dmax}} / \mathrm{Q}_{\mathrm{dsr}}
$$

- hourly non-uniformity under measuring conditions:

where:

$$
\mathrm{N}_{\mathrm{hp}}=\mathrm{Q}_{\mathrm{hmax}} / \mathrm{Q}_{\mathrm{hsr}}
$$

$\mathrm{Q}_{\mathrm{dmax}}-$ maximum daily water consumption, $\mathrm{m}^{3} / \mathrm{d}$,

$\mathrm{Q}_{\mathrm{dś}}-$ mean daily water consumption, $\mathrm{m}^{3} / \mathrm{d}$

$\mathrm{Q}_{\text {hmax }}$ - maximum hourly water consumption, $\mathrm{m}^{3} / \mathrm{h}$,

$\mathrm{Q}_{\text {hśr }}$ - mean hourly water consumption, $\mathrm{m}^{3} / \mathrm{h}$.

Daily and hourly non-uniformity factors are presented in table 1 and table 2 .

Table 1. Value of daily non-uniformity factor in multi-family buildings.

\begin{tabular}{|c|c|c|}
\hline $\mathbf{N}_{\mathrm{dp}}$ for $\mathbf{2 5 \%} \mathbf{- 7 5} \%$ fit & Mean value & Median \\
\hline $1.44-1.51$ & 1.48 & 1.49 \\
\hline
\end{tabular}

Table 2. Value of hourly non-uniformity factor in the studied multi-family buildings.

\begin{tabular}{|c|c|c|}
\hline $\mathbf{N}_{\text {hp }}$ for $\mathbf{2 5 \%} \mathbf{- 7 5 \%}$ fit & Mean value & Median \\
\hline $3.20-3.42$ & 3.31 & 3.32 \\
\hline
\end{tabular}

From the perspective of water meter selection, hourly flowrates are more meaningful, as they reflect actual maximum flows to be expected on a given water service pipe rather accurately. Thus, the hourly non-uniformity factor, determined under actual conditions, can be used to determine maximum flowrate and may serve as the basis for determining maximum flowrate on the service pipe and for water meter selection.

The next stage of analysis of the test results was to determine actual cold water consumption values per resident. Water consumption may differ in every household depending on appliances and awareness of how to save on utilities. Monthly and daily values of water demand per resident are presented in figure 4 and figure 5 . 


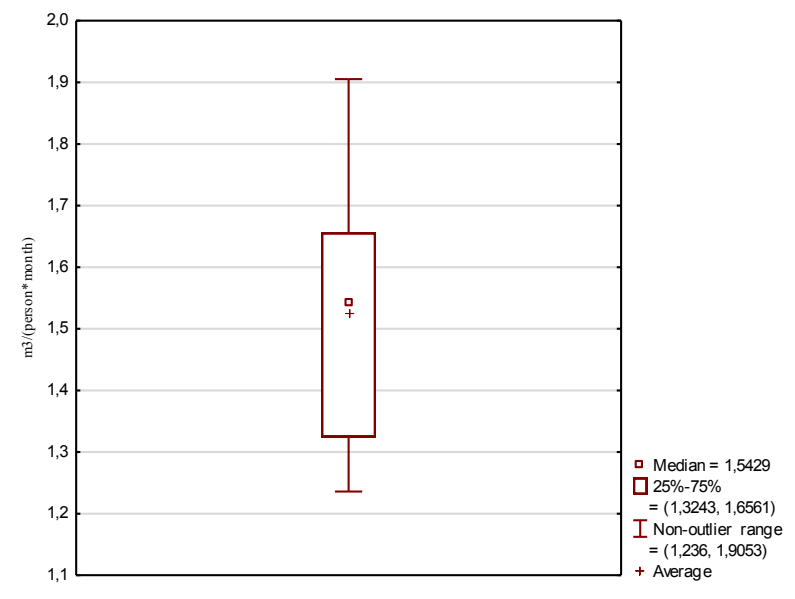

Fig. 4. Mean monthly cold water consumption per resident in the studied multi-family buildings.

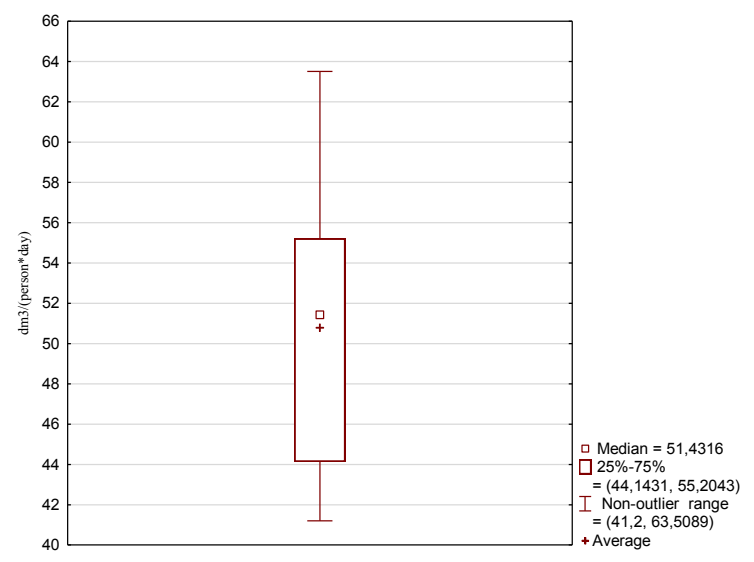

Fig. 5. Mean daily cold water consumption per resident in the studied multi-family buildings.

Unit water demand factors make it possible to calculate total water demand in the entire building. The monitored buildings had a mean monthly consumption equal to $1.52 \mathrm{~m}^{3} /$ resident month. To determine the actual water flowrate on the water service pipe of a building that is under construction in a manner that may serve for selecting a water meter with the proper measuring accuracy and thus contribute to limiting apparent losses, measured values should be multiplied by the number of residents, in a manner accounting for the time horizon.

\section{Summary}

Thanks to monitoring of quantities like minimum, mean and maximum volume stream, as well as water consumption, it can be assessed whether a given system is working correctly and measuring devices have been selected properly. Monitoring is the chief diagnostic tool for control of water distribution, stabilizing water meter management and allowing for rapid reaction in the event of emergencies and over the course of planned operations.

Monitoring a water service pipe in a multi-family building will make it possible to learn about the structure of water consumption, in detail, according to the intervals defining the 
accuracy of measuring devices. The charts that are obtained may serve as the basis for selecting water meters installed on water service pipes, thus limiting apparent losses.

Analysis of test results confirms that the studied buildings are characterized by variability of water demand within daily and hourly periods, as substantiated by monitoring of water flowrates in water service pipes. The determined actual daily and actual hourly non-uniformity factors can be used in water demand calculations for a given multi-family building.

Analysis showed a depressed structure of mean daily water consumption per person, amounting to $50.8 \mathrm{dm}^{3} /$ resident $\cdot$ day, on average.

After installation of a water meter, with readings based on residual magnetic field technology ensuring a linear measuring range, on the water service pipe in the studied buildings, apparent losses in the form of unregistered flows on the water service pipe reached up to $30 \%$ of daily consumption, even at the lowest flow values.

Studies have been carried out in the framework of working No. S/WBiIŚ/02/2014 and financed from the funds for science MNiSW.

\section{References}

1. M. Rimeika, R. Albrektien, Analysis of Apparent Water Losses, Case Study, The 9th International Conference ENVIRONMENTAL ENGINEERING, Vilnius, Lithuania (2014)

2. G.L. Richards, M.C. Jonson, S.L. Barfuss, J. Am. Water Works Ass. 105, 5 (2010)

3. W. Koral, Instal 5 (2005)

4. T. Cichoń, J. Królikowska, A. Królikowski, Gaz Woda Tech. 6 (2013)

5. F. Arregui, R. Cobacho, E. Cabrera, V. Espert, J. Water Res. Pl.-Asce 137, 1 (2011)

6. E.H. Johnson, Water SA 27, 4 (2001)

7. F. Arregui, E. Cabrera, R. Cobacho, Integrated Water Meter Management (IWA Publishing, 2006)

8. K. Billewicz, Smart metering - Intelligent measuring system (Wydawnictwo Naukowe PWN, Warszawa, 2011) (in Polish)

9. A. Criminisi, C. Fontanazza, G. Freni, G. Loggia, Water Sci. Technol. 60, 9 (2009)

10. P. Mukheibir, R. Stewart, D. Giurco, K. O’Halloran, Water J. 39, 8 (2012)

11. A. Lambert, R. McKenzie, Practical Experience in using the Infrastructure Leakage Index, IWA Conference Leakage Management - A Practical Approach, Cyprus, (2002)

12. A. Bochena, Treasures of the Earth - Water. Where does the water come from in tap? (Wydawnictwo Oulxl Media Sp. z o.o., Bydgoszcz, 2015) (in Polish)

13. T. Cichoń, J. Królikowska, Ecol. Eng. 48 (2016)

14. Water Audits and Loss Control Programs. Manual of Water Supply Practices M36. 3rd ed. AWWA. 283 (2009)

15. F. Arregui, E. Cabrera, R. Cobacho, J. Gracia-Serra, Water Pract. Tech. 1, 4 (2006)

16. P. Tuz, J. Gwoździej-Mazur, Rynek Instalacyjny 9 (2012)

17. P. Tuz, Rynek Instalacyjny 12 (2012)

18. Materials company Sensus 